\title{
Comparative genomic analysis of two-component regulatory proteins in Pseudomonas syringae José L Lavín ${ }^{1}$, Kristoffer Kiil2 ${ }^{2}$, Ohiana Resano ${ }^{1}$, David W Ussery ${ }^{2}$ and José A Oguiza*1
}

\author{
Address: ${ }^{1}$ Departamento de Producción Agraria, Universidad Pública de Navarra, 31006 Pamplona, Spain and ${ }^{2}$ Center for Biological Sequence \\ Analysis, Biocentrum-DTU, The Technical University of Denmark, DK-2800 Lyngby, Denmark \\ Email: José L Lavín - jluis.lavin@unavarra.es; Kristoffer Kiil - kiil@cbs.dtu.dk; Ohiana Resano - ohianara@hotmail.com; \\ David W Ussery - dave@cbs.dtu.dk; José A Oguiza* - jose.oguiza@unavarra.es \\ * Corresponding author
}

Published: 31 October 2007

BMC Genomics 2007, 8:397 doi:10.1 I86/I47I-2164-8-397

This article is available from: http://www.biomedcentral.com//47I-2/64/8/397

(c) 2007 Lavín et al; licensee BioMed Central Ltd.

This is an Open Access article distributed under the terms of the Creative Commons Attribution License (http://creativecommons.org/licenses/by/2.0), which permits unrestricted use, distribution, and reproduction in any medium, provided the original work is properly cited.

\begin{abstract}
Background: Pseudomonas syringae is a widespread bacterial plant pathogen, and strains of $P$. syringae may be assigned to different pathovars based on host specificity among different plant species. The genomes of P. syringae pv. syringae (Psy) B728a, pv. tomato (Pto) DC3000 and pv. phaseolicola $(P p h)$ I 448A have been recently sequenced providing a major resource for comparative genomic analysis. A mechanism commonly found in bacteria for signal transduction is the twocomponent system (TCS), which typically consists of a sensor histidine kinase (HK) and a response regulator (RR). P. syringae requires a complex array of TCS proteins to cope with diverse plant hosts, host responses, and environmental conditions.

Results: Based on the genomic data, pattern searches with Hidden Markov Model (HMM) profiles have been used to identify putative HKs and RRs. The genomes of Psy B728a, Pto DC3000 and Pph I448A were found to contain a large number of genes encoding TCS proteins, and a core of complete TCS proteins were shared between these genomes: 30 putative TCS clusters, II orphan HKs, 33 orphan RRs, and 16 hybrid HKs. A close analysis of the distribution of genes encoding TCS proteins revealed important differences in TCS proteins among the three $P$. syringae pathovars.

Conclusion: In this article we present a thorough analysis of the identification and distribution of TCS proteins among the sequenced genomes of $P$. syringae. We have identified differences in TCS proteins among the three $P$. syringae pathovars that may contribute to their diverse host ranges and association with plant hosts. The identification and analysis of the repertoire of TCS proteins in the genomes of $P$. syringae pathovars constitute a basis for future functional genomic studies of the signal transduction pathways in this important bacterial phytopathogen.
\end{abstract}

\section{Background}

Bacterial signal transduction pathways sense the cellular external environment and regulate cellular functions in response to environmental signals. A mechanism com- monly found in bacteria for signal transduction is the twocomponent system (TCS). Bacterial TCSs are common components of complex regulatory networks and cascades, often associated with global regulation as well as 
with regulation of virulence. TCS genes are typically located within the same operon encoding two signalling proteins: a transmembrane sensor histidine kinase (HK) and a cytoplasmic response regulator (RR), which may sometimes be carried by a single polypeptide to form the hybrid HKs [1]. The mechanism of signal transduction by TCS proteins is based on phosphotransfer reactions between histidine $(\mathrm{H})$ and aspartate $(\mathrm{D})$ residues in highly conserved signalling domains of the HKs and their cognate RRs. TCS proteins have a modular organization, which may give rise to highly complex structures, but the core structures and activities are maintained [2]. HKs are typically organized as homodimers with two functionally and structurally distinct domains: a highly variable N-terminal extracytoplasmic sensory domain, and a more conserved C-terminal cytoplasmic transmitter domain, also known as the dimerization/phosphoacceptor domain $[2,3]$. The sensor domain varies in length and amino acid sequence from one HK to another, conferring specificity for different environmental stimuli. In most HKs, the transmitter domain shows high sequence conservation, especially within a set of six recognizable motifs or boxes designated H, N, F, G1, G2, and G3. In particular, the H box contains an invariant $\mathrm{H}$ residue that is autophosphorylated in an ATP-dependent manner [4]. In contrast, CheA-like HKs that function in chemotaxis lack the sensor domain and differ from other HKs in their domain constitution and organization, where the $\mathrm{H}$ box of the transmitter domain resides at the $\mathrm{N}$-terminal end of the protein [58]. LytS-like HKs also differ significantly in their domain architecture from other HKs [9-11]. RRs generally contain at least two functional domains: a conserved $\mathrm{N}$-terminal receiver domain (REC domain) that is phosphorylated by the $\mathrm{HK}$ at a strictly conserved $\mathrm{D}$ residue, and one or more variable C-terminal output domains [12]. Modulation of the phosphorylated state of the RR controls either expression of the target genes or cellular behaviour. The principal type of bacterial RRs are transcription factors that regulate gene-expression with DNA-binding helix-turnhelix $(\mathrm{HTH})$ output domains $[1,3,12,13]$. Hybrid HKs contain both a HK transmitter domain and a REC domain in a single large polypeptide, and are characterized by multi-step phosphotransfer reactions $[1,7,14]$.

The availability of complete genome sequences for a continually growing number of bacteria has allowed the definitive assessment that TCS proteins are present in almost all bacterial species $[1,8,12]$. Genomic analyses demonstrate the enormous impact of TCSs on environmental adaptation of bacteria, and reveal a wide variation of HK and RR numbers between different bacterial species $[7,8,12,15-20]$.

The bacterial plant pathogen Pseudomonas syringae causes disease on a variety of plant species, and strains of $P$. syringae have been classified into different pathovars depending on their host range among different plant species [21]. Infection of host plants by $P$. syringae involves growth on leaf surfaces as an epiphyte, that enters plant leaves through stomata, multiplies to large populations in the apoplast and produces disease symptoms [21,22]. $P$. syringae injects effector proteins into the cytoplasm of plant cells by means of the Hrp type III secretion system [21]. Genome comparisons indicate that P. syringae is significantly different from other Pseudomonas species $[23,24]$, suggesting that in the adaptation to the phytopathogenic lifestyle its genome must have undergone fundamental changes without a reduction in size. The complete genomic sequences of three economically important pathovars of this plant pathogenic bacteria have been determined: $P$. syringae pv. tomato (Pto) DC3000, pv. syringae (Psy) B728a and pv. phaseolicola (Pph) 1448A [25-27]. In these genomes, over 10 to $12 \%$ of the genes are dedicated to regulation, which may reflect the need for rapid adaptation to the diverse environments encountered during epiphytic growth, plant colonization and pathogenesis [25-27]. Genome analyses of these $P$. syringae pathovars revealed fewer extracytoplasmic function (ECF) sigma factors (10 ECF sigma factors) than in related Pseudomonas with different lifestyles [24]. Recently, analysis of the Pto DC3000 genome sequence allowed the identification of 69 HKs $[28,29]$ and 71 RRs, 21 of which were hybrid HKs [12]. In a different study not including CheA-like HKs, 64 HKs were identified in Pto DC3000, 20 of which were hybrid HKs [30]. Hence, $P$. syringae requires a complex array of TCS proteins to cope with diverse plant hosts, host responses, and environmental conditions. The availability of complete genomic sequences of three different $P$. syringae pathovars makes it possible to conduct this comparative genomic study to identify and analyse the TCS proteins of $P$. syringae.

\section{Results and Discussion}

\section{Distribution of TCS proteins in P. syringae}

The putative HKs and RRs in Psy B728a, Pto DC3000 and Pph 1448A were identified by searching the complete genome sequences for proteins containing $\mathrm{HK}$ and RR domains using Pfam HMM profiles. Four CheA-like HKs in each $P$. syringae genome were identified in BLASTP searches using as template the CheA HK of E. coli [31] (Table 1). In addition, BLASTP searches of the HKs and RRs found in each $P$. syringae pathovar against the genomes of the other two pathovars allowed the identification of additional HKs and RRs. The genomes of P. syringae pathovars were found to contain large numbers of genes encoding TCS proteins: $68 \mathrm{HKs}$ and 93 RRs in Psy B728a, 69 HKs and 95 RRs in Pto DC3000, and 70 HKs and 92 RRs in Pph 1448A (Table 1; see Additional File 1 and 2). The number of genes encoding hybrid HKs (RECHKs) was 20 in Psy B728a, 22 in Pto DC3000 and 24 in 
Table I: Distribution of HKs and RRs found in the genomes of $P$. syringae pv. syringae B728a, pv. tomato DC3000 and pv. phaseolicola 1448A.

\begin{tabular}{|c|c|c|c|}
\hline HK type/RR type & P. syringae pv. syringae B728a & P. syringae pv. tomato $\mathrm{DC} 3000$ & $\begin{array}{c}\text { P. syringae pv. phaseolicola } \\
\text { I 448A }\end{array}$ \\
\hline \multicolumn{4}{|l|}{ Histidine kinases } \\
\hline Type IA & 22 & 20 & 21 \\
\hline Type IB & 13 & 15 & 15 \\
\hline Type IC & 20 & 21 & 22 \\
\hline Type III & 2 & 2 & 2 \\
\hline CheA-like & 4 & 4 & 4 \\
\hline GAF-HK & 6 & 6 & 5 \\
\hline LytS-like & I & I & I \\
\hline Total HKs & 68 & 69 & 70 \\
\hline \multicolumn{4}{|l|}{ Response regulators } \\
\hline Stand-alone REC & 12 & 13 & 10 \\
\hline OmpR-like & 22 & 20 & 19 \\
\hline NarL-like & 9 & 12 & 10 \\
\hline NtrC-like & 11 & 11 & 11 \\
\hline LytR-like & 2 & 2 & 2 \\
\hline PrrA-like & 1 & 1 & I \\
\hline PleD-like & 5 & 4 & 5 \\
\hline RsbU-like & 2 & 2 & 2 \\
\hline CheB-like & 3 & 3 & 3 \\
\hline CheC-like & I & I & I \\
\hline CheW-like & 2 & 2 & 2 \\
\hline VieA-like & I & I & I \\
\hline VieB-like & I & I & I \\
\hline AmiR-like & I & -- & -- \\
\hline REC-HK (hybrid HK) & 20 & 22 & 24 \\
\hline Total RRs & 93 & 95 & 92 \\
\hline
\end{tabular}

Pph 1448A (Tables 1 and 4). The HMM search method used in this work retrieved hybrid HKs as well as RRs (Table 1). No TCS proteins were identified on any of the plasmids of Pto DC3000 and Pph 1448A. In recent studies, similar numbers of TCS proteins for Pto DC3000 have been reported: $69 \mathrm{HKs}[28,29]$ and 71 RRs, 21 of which were hybrid HKs [12]; or $64 \mathrm{HKs}$ in a study not including CheA-like HKs, 20 of which where hybrid HKs [30]. Although the number of ECF sigma factors in all three $P$. syringae genomes (10 ECF sigma factors) is only about half that found in other Pseudomonas species [24,32], the number of TCS proteins is close to that found in other Pseudomonas genomes [33].

HK and RR genes were scattered over the entire chromosomes of the three $P$. syringae pathovars. Conservation of the genetic organization between $\mathrm{HK}$ and RR genes was analysed in the genomes of Psy B728a, Pto DC3000 and Pph 1448A allowing the identification of gene clusters containing HKs and RRs that constitute putative TCSs (Table 2). Like in other bacterial species, many P. syringae HKs and RRs were encoded by clusters of adjacent genes: 37 putative clusters of complete TCS genes in Psy B728a, 34 in Pto DC3000, and 33 in Pph 1448A (Table 2). For the remaining $H K$ or RR genes, their partner genes could not be predicted from genetic organization and, therefore, they were considered as orphan HKs or RRs. The orphan HKs were 11 in each $P$. syringae genome, and the number of genes encoding orphan RRs was very high: 36 in Psy B728a, 38 in Pto DC3000 and 35 in Pph 1448A (Table 3). Finally, the comparative genomic analysis allowed the identification of a core of complete TCS protein orthologues among the three $P$. syringae pathovars, that is composed by 30 putative TCS clusters (HK and RR) (Table 2), 11 orphan HKs, 33 orphan RRs (Table 3), and 16 hybrid HKs (Table 4).

\section{Classification of HKs}

HKs have been classified on the basis of phylogenetic analyses and the sequence relationships of the residues surrounding the H-box $[7,8,17,34]$. Furthermore, several new domains with putative biological functions have been described in HKs, and domain architecture has proven particularly informative for analysing multidomain proteins involved in signal transduction $[2,11,12,35]$. The phylogenetic analysis and examination of the region around the $\mathrm{H}$ box of $P$. syringae HKs showed that three of the five major HK types found in E. coli [8] were present in P. syringae: Type I (IA, IB, IC), III, and CheA-like HKs (Table 1; see Additional File 1). In contrast, 
Table 2: Putative TCS gene clusters in the genomes of $P$. syringae pv. syringae B728a, pv. tomato DC3000 and pv. phaseolicola I448A.

\begin{tabular}{|c|c|c|c|c|c|c|}
\hline \multicolumn{3}{|c|}{ Histidine kinase/Response regulator } & \multirow[t]{2}{*}{ Protein name $^{a}$} & \multirow[t]{2}{*}{ Organization $^{b}$} & \multirow[t]{2}{*}{ HK type } & \multirow[t]{2}{*}{ RR type } \\
\hline Psy B728a & Pto DC3000 & Pph I448A & & & & \\
\hline PSYR0064/0063 & PSPTO0I26/0I 27 & PSPPH0070/0069 & FimS/AlgR & $H R$ & LytS-like & LytR-like \\
\hline PSYR0259/0258 & PSPTO0329/0328 & PSPPH0247/0246 & EnvZ/OmpR & RH & IA & OmpR-like \\
\hline PSYR0264/0263 & PSPTO0335/0334 & PSPPH0253/0252 & $--/ A \operatorname{lgB}$ & $\mathrm{RH}$ & IA & NtrC-like \\
\hline PSYR0723/0722 & PSPTO0824/0823 & PSPPH0737/0736 & PilS/PilR & $\mathrm{RH}$ & IC & NtrC-like \\
\hline PSYR0786/0788 & PSPTO0913/0915 & PSPPH0805/0807 & CheAl/CheYl & $\mathrm{RH}^{\mathrm{c}}$ & CheA-like & Stand-alone REC \\
\hline PSYR0832/083। & PSPTO0965/0964 & PSPPH0858/0857 & $--/--$ & HR & IC & NtrC-like \\
\hline PSYRII00/I099 & $--/--$ & PSPPHII68/II67 & $--/--$ & $\mathrm{RH}^{\mathrm{d}}$ & IB & PleD-like \\
\hline PSYRIIII/IIIII & PSPTOI $291 / / 290$ & PSPPHII80/II79 & $--/ G \mid t R$ & $\mathrm{RH}$ & IA & OmpR-like \\
\hline PSYRI I $26 / I 127$ & PSPTOI $306 / 1307$ & PSPPHII94/II 95 & $--/--$ & $\mathrm{RH}$ & IA & OmpR-like \\
\hline PSYRI498/I497 & --/-- & --/-- & CopS/CopR & RH & IA & OmpR-like \\
\hline PSYRI94I/I940 & PSPTO2। $31 / 2130$ & PSPPHI907/I906 & $--/--$ & $H R$ & III & NarL-like \\
\hline PSYR203I/2032 & PSPTO2222/2223 & PSPPH2003/2004 & RhpS/RhpR & $\mathrm{RH}$ & IA & OmpR-like \\
\hline PSYR2050/205I & PSPTO2245/2246 & PSPPH202I/2022 & $\mathrm{KdpD} / \mathrm{KdpE}$ & $H R$ & IA & OmpR-like \\
\hline PSYR2374/2375 & PSPTO2642/2643 & PSPPH25I0/--e & $--/--$ & $\mathrm{RH}$ & IA & OmpR-like \\
\hline PSYR2385/2384 & PSPTO2652/265I & $--/-$ & BphP2/-- & $\mathrm{HR}$ & GAF-HK & Stand-alone REC \\
\hline PSYR2867/2868 & PSPTO2983/--e & PSPPH2377/2376 & BaeS2/BaeSI & $H R$ & $\mathrm{IA}$ & OmpR-like \\
\hline PSYR3085/3084 & $--/--$ & PSPPH2980/--e & $--/--$ & $\mathrm{RH}$ & IA & OmpR-like \\
\hline PSYR3 I 28/3 I 27 & PSPTO3298/3297 & PSPPH304I/3040 & --/-- & $\mathrm{RH}$ & IA & OmpR-like \\
\hline PSYR32II/32I 2 & PSPTO3380/338I & PSPPH3 | 26/3 I 27 & --/-- & RH & IA & OmpR-like \\
\hline PSYR3375/3374 & PSPTO3604/3603 & PSPPH3295/3294 & --/-- & $\mathrm{RH}$ & IA & OmpR-like \\
\hline PSYR3434/3436 & PSPTO। $982 / 1980$ & PSPPH3360/3362 & CheA2/CheY2 & $\mathrm{RH}^{\mathrm{c}}$ & CheA-like & Stand-alone REC \\
\hline PSYR3460/3459 & PSPTOI955/1956 & PSPPH3386/3385 & FleS/FleR & HR & IC & NtrC-like \\
\hline PSYR35I2/35II & PSPTOI893/I894 & PSPPH3454/3453 & QseC/QseB & $\mathrm{RH}$ & IA & OmpR-like \\
\hline PSYR3708/3709 & PSPTOI680/I679 & PSPPH3729/3730 & PhoQ/PhoP & $\mathrm{RH}$ & IA & OmpR-like \\
\hline PSYR37I5/37I6 & PSPTOI673/I672 & PSPPH3736/3737 & $--/ R s t A$ & RH & IA & OmpR-like \\
\hline PSYR3792/3793 & $--/-$ & PSPPHI46I//460 & $--/ C p \times R$ & $\mathrm{RH}$ & IA & OmpR-like \\
\hline PSYR3912/3913 & PSPTO4I75/4I76 & PSPPH3906/3907 & $--/--$ & $H R$ & IC & NtrC-like \\
\hline PSYR3964/3965 & PSPTO4230/423I & PSPPH3961/3962 & TctE/TctD & $\mathrm{RH}$ & IA & OmpR-like \\
\hline PSYR3994/3995 & PSPTO429I/4292 & PSPPH $4001 / 4002$ & $--/--$ & $\mathrm{HR}$ & IC & NtrC-like \\
\hline PSYR4069/4070 & PSPTO4373/4374 & PSPPH4074/4075 & Cols/ColR & $\mathrm{RH}$ & IA & OmpR-like \\
\hline PSYR423I/4230 & PSPTO4554/4553 & PSPPH4256/4255 & $--/--$ & $H R$ & IC & PrrA-like \\
\hline PSYR4619/4618 & PSPTO0559/0560 & PSPPH064I/0642 & --/-- & $H R$ & III & NarL-like \\
\hline PSYR4799/4800 & PSPTO0379/0378 & PSPPH4827/4828 & --/-- & RH & IA & OmpR-like \\
\hline PSYR482I/4822 & PSPTO0353/0352 & PSPPH4852/4853 & $\mathrm{NtrB} / \mathrm{N} \operatorname{trC}$ & $H R$ & IC & NtrC-like \\
\hline PSYR4937/4938 & PSPTO5398/5399 & PSPPH0I47/0।46 & --/-- & $H R$ & IC & NtrC-like \\
\hline PSYR5033/5032 & PSPTO5478/5477 & PSPPH5II5/5।I4 & PhoR/PhoB & $\mathrm{RH}$ & IA & OmpR-like \\
\hline PSYR5089/5088 & PSPTO5549/5548 & PSPPH5I72/5I7I & $--/--$ & $H R$ & IC & LytR-like \\
\hline --/-- & PSPTO0785/0786 & $--/--$ & --/-- & $H R$ & IA & OmpR-like \\
\hline --/-- & PSPTO4705/4704 & $--/--$ & CorS/CorR & RH & IB & NarL-like \\
\hline$--/--$ & PSPTO5573/5574e & $--/--$ & --/-- & $H R$ & IC & OmpR-like \\
\hline
\end{tabular}

a Whenever a HK or RR of $P$. syringae has been assigned a function in the literature and/or an annotation in databases, the corresponding protein name is mentioned; 'organization of each TCS on P. syringae genomes (HR, 5' histidine kinase-3' response regulator; RH, 5' response regulator-3' histidine kinase); ${ }^{c}$ an additional gene is located in between the RR and HK genes; ${ }^{d} \mathrm{HR}$ in P. syringae pv. phaseolicola I448A; e genes with disrupted reading frames.

Type II and IV HKs were totally absent from P. syringae. However, the LytS-like HK FimS/AlgZ and HKs containing GAF domains did not cluster within any of the defined HK types of E. coli [8], and formed two separate HK groups: LytS-like HKs and GAF-HKs. GAF sensor domains are commonly found cytoplasmic signalling domains in the $\mathrm{N}$-terminal region of HKs [2,34], and appear to act as binding sites for small ligands, such as cyclic nucleotides (CAMP and cGMP) and small molecules, which modulate the catalytic activity of the target protein [36,37]. In addition, analysis of domain architecture of $P$. syringae HKs showed a conserved core structure for each HK type in $P$. syringae (Figure 1). The conserved core of Type III HKs and LytS-like HKs only had a HK-like ATPase (HATPase_c) catalytic domain and a His_kinase domain, respectively. The conserved core of CheA-like HKs contained a C-terminal CheA regulatory domain but lacked the HisKA domain. The conserved core of Type I HKs and GAF-HKs 
Table 3: Orphan HK and RR genes in the genomes of P. syringae pv. syringae B728a, pv. tomato DC3000 and pv. phaseolicola I448A.

\begin{tabular}{|c|c|c|c|}
\hline P. syringae pv. syringae B728a & P. syringae pv. tomato $\mathrm{DC} 3000$ & $\begin{array}{c}\text { P. syringae pv. phaseolicola } \\
\text { I448A }\end{array}$ & HK/RR type \\
\hline \multicolumn{4}{|l|}{ Orphan HKs } \\
\hline PSYRI9I8 & PSPTO2I 23 & PSPPHI874 & GAF-HK \\
\hline PSYR2978 & РSPTO3।II & PSPPH2262 & IC \\
\hline PSYR3060 & PSPTO3।95 & PSPPH 2185 & IC \\
\hline PSYR3504/BphPI & PSPTOI902 & PSPPH3446 & GAF-HK \\
\hline PSYR3591 & PSPTOI803 & PSPPH 3550 & IA \\
\hline PSYR3773 & PSPTOI606 & PSPPHI 480 & GAF-HK \\
\hline PSYR3774 & PSPTOI605 & PSPPHI479 & GAF-HK \\
\hline PSYR4089 & PSPTO4395 & PSPPH4095 & IC \\
\hline PSYR4339 & PSPTO4796 & PSPPH438I & IB \\
\hline PSYR4373 & PSPTO4833 & PSPPH44I6 & IC \\
\hline PSYR4439 & PSPTO4896 & PSPPH448I & GAF-HK \\
\hline \multicolumn{4}{|l|}{ Orphan RRs } \\
\hline PSYR0089 & PSPTO0303 & PSPPH0094 & Stand-alone REC \\
\hline PSYR0488/PilG & PSPTO5034 & PSPPH0479 & Stand-alone REC \\
\hline PSYR0489/PilH & PSPTO5033 & PSPPH0480 & Stand-alone REC \\
\hline PSYR0509 & PSPTO50I4 & PSPPH0499 & PleD-like \\
\hline PSYR078I/CheBI & PSPTO0908 & PSPPH0800 & CheB-like \\
\hline PSYR0886 & PSPTOI039 & PSPPH0923 & CheC-like \\
\hline PSYRI098 & PSPTOI 278 & PSPPHII 66 & PleD-like \\
\hline PSYRII39 & PSPTOI323 & PSPPHI 207 & CheW-like \\
\hline PSYRII90/HrpR & PSPTOI379 & PSPPHI 270 & NtrC-like \\
\hline PSYRII9I/HrpS & PSPTOI380 & PSPPHI27I & NtrC-like \\
\hline PSYRI 293 & PSPTOI 483 & PSPPHI 363 & VieA-like \\
\hline PSYRI 294 & PSPTOI 484 & PSPPHI 364 & NarL-like \\
\hline PSYRI308/CheB2 & PSPTOI498 & PSPPH3876 & CheB-like \\
\hline PSYRI309/WspR & PSPTOI499 & PSPPH3875 & PleD-like \\
\hline PSYRI 384 & PSPTO4027 & PSPPH 3800 & NarL-like \\
\hline PSYRI9I2 & PSPTO2117 & PSPPHI 867 & RsbU-like \\
\hline PSYRI938 & PSPTO2। 28 & PSPPHI904 & Stand-alone REC \\
\hline PSYR2।I4 & -- & -- & NarL-like \\
\hline PSYR2II5 & PSPTO2330 & -- & Stand-alone REC \\
\hline PSYR2449 & PSPTO2716 & PSPPH2605 & Stand-alone REC \\
\hline PSYR2897/GacA & PSPTO3024 & PSPPH2328 & NarL-like \\
\hline PSYR2939 & -- & -- & AmiR-like \\
\hline PSYR309I & PSPTO3245 & PSPPH2995 & OmpR-like \\
\hline PSYR3299 & PSPTO3526 & PSPPH 3220 & NarL-like \\
\hline PSYR3433/CheB3 & PSPTOI983 & PSPPH3359 & CheB-like \\
\hline PSYR345I & PSPTOI964 & PSPPH 3377 & RsbU-like \\
\hline PSYR346I/FleQ & PSPTOI954 & PSPPH3387 & NtrC-like \\
\hline PSYR3486 & PSPTOI927 & PSPPH 3413 & CheW-like \\
\hline PSYR3496 & PSPTOI9II & PSPPH 3428 & VieB-like \\
\hline PSYR3589 & PSPTOI806 & PSPPH 3547 & OmpR-like \\
\hline PSYR3890 & PSPTO4I5I & PSPPHI 374 & NarL-like \\
\hline PSYR4376 & PSPTO4836 & PSPPH 4419 & NarL-like \\
\hline PSYR4377 & PSPTO4837 & PSPPH4420 & PleD-like \\
\hline PSYR4388 & PSPTO4848 & PSPPH443I & Stand-alone REC \\
\hline PSYR470I & PSPTO0472 & PSPPH4737 & Stand-alone REC \\
\hline PSYR5036 & PSPTO5482 & PSPPH5II8 & Stand-alone REC \\
\hline-- & PSPTO0897 & PSPPH424I & NarL-like \\
\hline-- & PSPTO2329a & -- & Stand-alone REC \\
\hline-- & PSPTO4080 & -- & NarL-like \\
\hline-- & PSPTO4706/CorP & -- & NarL-like \\
\hline-- & -- & PSPPH0778 & NarL-like \\
\hline
\end{tabular}

a Genes with disrupted reading frames. 
Table 4: Hybrid HK genes in the genomes of P. syringae pv. syringae B728a, pv. tomato DC3000 and pv. phaseolicola I448A.

\begin{tabular}{|c|c|c|c|}
\hline P. syringae pv. syringae B728a & P. syringae pv. tomato DC3000 & $\begin{array}{c}\text { P. syringae pv. phaseolicola } \\
\text { I 448A }\end{array}$ & HK type \\
\hline PSYR0492 & PSPTO5030 & PSPPH0483 & CheA-like \\
\hline PSYRI 292 & PSPTOI482 & PSPPHI362a & IB \\
\hline PSYRI300 & PSPTOI490 & PSPPHI37I & IC \\
\hline PSYRI307 & PSPTOI497 & PSPPH3877 & CheA-like \\
\hline PSYRI585 & PSPTO3900 & PSPPHI568 & IB \\
\hline PSYRI778 & PSPTO3696 & PSPPHI729 & IC \\
\hline PSYRI939 & PSPTO2। 29 & PSPPHI905 & IB \\
\hline PSYR202I & PSPTO22 12 & PSPPHI99|a & IB \\
\hline PSYR2II3 & PSPTO2326a & $\mathrm{PSPPH} 2083^{\mathrm{a}}$ & IB \\
\hline PSYR2445 & PSPTO27I2 & PSPPH260I & IB \\
\hline PSYR2448 & PSPTO27I5 & PSPPH 2604 & IB \\
\hline PSYR2450 & PSPTO27I7 & PSPPH2606 & IC \\
\hline PSYR2700 & PSPTO2896 & PSPPH 2483 & IC \\
\hline PSYR2940 & -- & -- & IB \\
\hline PSYR3355 & PSPTO3584 & PSPPH 3276 & IC \\
\hline PSYR3532 & PSPTOI870 & PSPPH3473 & IC \\
\hline PSYR36I 2 & PSPTOI782 & PSPPH 3628 & IB \\
\hline PSYR3698/GacS & PSPTOI69I & PSPPH 3719 & IB \\
\hline PSYR3996 & PSPTO4293 & PSPPH4003 & IC \\
\hline PSYR4408 & PSPTO4868 & PSPPH445I & IB \\
\hline-- & PSPTO0896 & PSPPH4242 & IB \\
\hline-- & PSPTO0898 & PSPPH0796 & IB \\
\hline-- & PSPTO4079 & -- & IB \\
\hline-- & -- & PSPPH0770 & IB \\
\hline-- & -- & PSPPH0944 & IC \\
\hline-- & -- & PSPPHI26I & IC \\
\hline
\end{tabular}

a Genes with disrupted reading frames.

had a central region with HisKA and HATPase_c domains fused to additional domains on the N-terminal end: a HAMP domain in Type IA, a PAS domain in Type IC, and GAF plus phytochrome (PHY) binding domains in GAFHKs (Figure 1).

Orphan HKs fell into two HK types: Type I (IA, IB and IC), and GAF-HKs (Table 3); and hybrid HKs of P. syringae belong either to the Type I (IB and IC) or CheA-like HKs (Table 4). PSYR3504 (BphP1) and PSYR2385 (BphP2) HKs have been previously described as bacteriophytochromes (BphPs) that belong to the HWE_HK family $[4,38]$. Similar to other BphPs, the bphP1 (PSYR3504) gene of $P$. syringae pathovars is located in an operon downstream from a $b$ phO gene, encoding a putative heme oxigenase.

\section{Classification of RRs}

RRs show a great variety of output domains and domain combinations. Recently, bacterial and archaeal RRs have been classified into families based in their domain architectures [12]. RRs typically consist of an N-terminal REC domain fused to a C-terminal HTH DNA-binding output domain (OmpR, NarL, NtrC, LytR, AraC, Spo0A, Fis, YcbB, RpoE, and MerR) that activates or represses transcription of specific target genes [2,12]. In addition, prokaryotic genomes encode a variety of RRs with unusual domain organization: RRs with enzymatic output domains (GGDEF, EAL, HD-GYP, CheB, CheC, PP2C, and HisKA), RRs with RNA-binding output domains (ANTAR and CsrA), RRs with protein- or ligand-binding output domains (CheW, PAS, GAF, TPR, CAP_ED, and Hpt), RRs with the REC domain as a stand-alone module, and RRs with domains of unknown function [12]. The RRs identified from the genomes of $P$. syringae pathovars were assigned to these different RR families [12] according to the domain architecture and phylogenetic analysis (Table 1; see Additional File 2).

Bacterial RRs without a REC domain are extremely rare, but a number of enhancer-binding proteins (EBPs) lack the REC domain and normally function as RRs [39]. EBPs are involved in the activation of the bacterial transcription by interaction with the sigma-54 RNA polymerase holoenzyme [40]. In P. syringae, the HrpR and HrpS proteins show a high sequence similarity to the NtrC family of transcriptional RRs and have been previously identified as unusual EBPs lacking the N-terminal REC domain; however, similar to other EBPs, they retain the domain that interacts with the sigma-54 RNA polymerase 


\section{HK type Conserved core structure}

Type IA

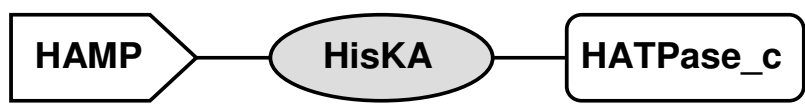

Type IB

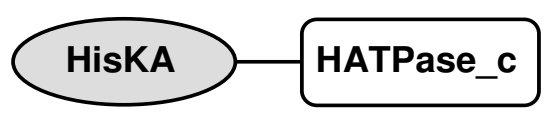

Type IB

(hybrid)

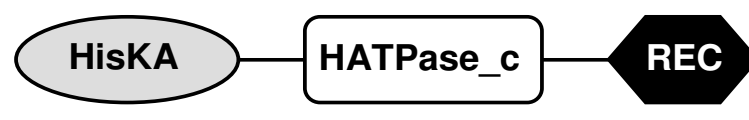

Type IC

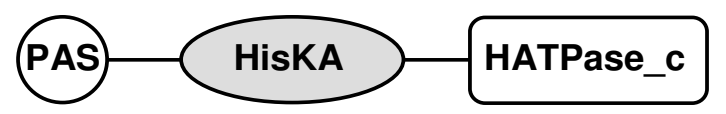

Type IC

(hybrid)

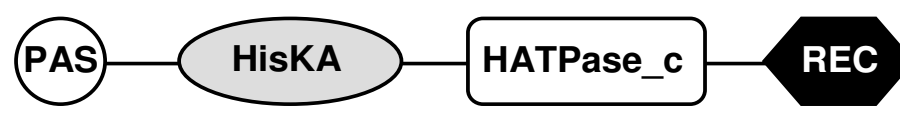

Type III

\section{HATPase_c}

CheA-like

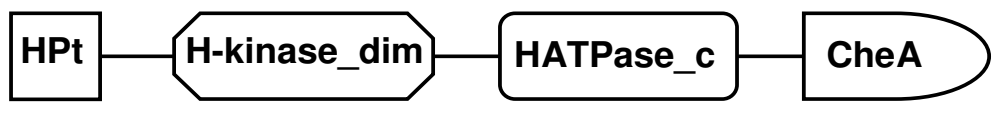

CheA-like

(hybrid)

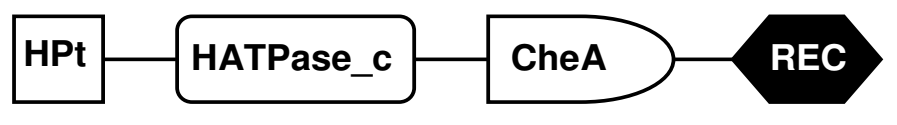

GAF-HK

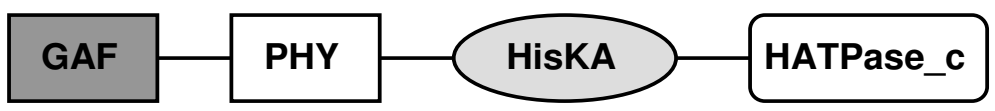

LytS-like

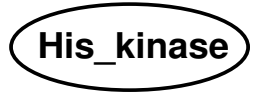

Figure I

Schematic representation of the conserved core structures found in $P$. syringae HK types. The domains are not drawn to scale. HAMP, domain found in $\underline{H K}$ s, Adenylyl cyclases, Methyl binding proteins and Phosphatases (PF00672); HisKA, HK dimerization/phosphoaceptor domain (PF005 I2); HATPase_c, HK-type ATPase catalytic domain (PF025 I8); REC, receiver domain (PF00072); PAS, signal sensor domain (PF00989); HPt, Histidine-containing Phosphotransfer domain (PF01627); Hkinase_dim, HK homodimeric domain (PF02895); GAF, signal sensor domain (PF01590); PHY, phytochrome domain (PF00360); His_kinase, region within bacterial HKs (PF06850). 
holoenzyme plus the C-terminal DNA-binding domain [39-42]. In addition, the NarL-like RR CorP of Pto DC3000 that is involved in the regulation of coronatine biosynthesis $[43,44]$ also lacks the REC domain. Thus, HrpR, HrpS and CorP proteins were not identified during the search of RRs in P. syringae genomes with the HMM profile that targets the RR REC domain, nevertheless these proteins were considered orphan RRs (Table 3).

\section{Differences in TCS genes among pathovars that may contribute to plant host specificity}

A close analysis of the distribution of genes encoding TCS proteins revealed that there are important differences in TCS proteins among the three pathovars of $P$. syringae that may contribute to their diverse host ranges and association with particular host plants. A number of the identified TCS genes were unique to each $P$. syringae pathovar without counterparts in the other two pathovars. The corRSP regulatory region (PSPTO4704-4706) of coronatine biosynthesis and the copRS TCS (PSYR1497/1498) regulating copper resistance were only present in Pto DC3000 and Psy B728a, respectively. Other TCS genes unique to each P. syringae pathovar were: PSYR2114, PSYR2939, PSYR2940 and PSYR3084 in Psy B728a; PSPTO0785/0786, PSPTO2329, PSPTO4079, PSPTO4080 and PSPTO5573/5574 in Pto DC3000; PSPPH0770, PSPPH0778, PSPPH0944 and PSPPH1261 in Pph 1448A. The unique hybrid HKs PSPPH0770 and PSPPH0944 were flanked by transposases. However, the unique RRs PSPTO2329 and PSPTO5574 were disrupted by transposases $[25,27]$, and it is unlikely that these genes encode functional products. Finally, 11 TCS proteins were only shared between two of these $P$. syringae pathovars.

Variations among P. syringae pathovars were also produced by the insertion of mobile genetic elements or point mutations in TCS genes resulting in disrupted reading frames. PSPTO2326 and PSPPH2083 encoded truncated hybrid HKs by comparison with the length of their orthologue PSYR2113 (Table 4) that is located next to the unique RR PSYR2114. PSPTO2326 and PSPPH2083 were located adjacent to a transposase and to a site-specific recombinase, respectively. Probably these elements caused the disrupted hybrid HKs and the lack of PSYR2114 orthologues in Pto DC3000 and Pph 1448A. Similarly, PSPTO2983 (baeS2) and PSPPH2510 encoded truncated HKs compared to the length of their P. syringae orthologues, and PSPPH2980 was interrupted by an ISPsy18 transposase. PSPTO2983, PSPPH2510 and PSPPH2980 HKs were unpaired without a RR gene in its vicinity, whereas their $P$. syringae orthologues are located on TCS gene clusters with adjacent RRs (Table 2).

Although the PSPPH1362 gene was disrupted by an authentic frameshift, Psy B728a (PSYR1292) and Pto
DC3000 (PSPTO1482) orthologues encoded intact hybrid HKs with similarity to BvgS of Bordetella species that controls the regulation of many virulence factors [45]. In each pathovar, these hybrid HK genes were adjacent to orphan RR genes transcribed in the same direction (PSYR1293, PSPTO1482 and PSPPH1363), and their encoded proteins exhibited significant homology to the PvrR RR of P. aeruginosa PA14 which controls antibiotic susceptibility and biofilm formation [46], and to the virulence related protein VieA of Vibrio cholerae [47].

\section{Conclusion}

In this article we present a thorough analysis of the identification and distribution of TCS proteins among the sequenced genomes of $P$. syringae. A large set of TCS proteins is required for the capacity of $P$. syringae to detect and adapt to changing environments during plant association and pathogenesis. Moreover, P. syringae has been isolated from non-plant environments such as river epilithon (rock-attached biofilms) [48] in which TCS proteins may have also important regulatory roles. $P$. syringae pathovars posses between 68-70 HKs and 92-95 RRs (Table 1), however there is little information describing their regulatory functions and the major part of these TCS proteins is uncharacterized. Many of the TCS proteins investigated so far in $P$. syringae have been shown to be involved in plant pathogenicity and association with host plants. The orphan RRs HrpR and HrpS are involved in a complex regulatory cascade that activates the transcription of the Hrp type III secretion genes and all known effector genes $[42,49]$. Expression of the type III secretion genes and effector genes is also regulated by the particular TCS GacA/ GacS [50] and the RhpRS system [51]. Furthermore, the GacA/GacS system controls the expression of a variety of virulence factors, including protease and syringomycin biosynthesis [52]. The TCS CopRS and the modified CorRSP system regulate resistance to copper [53] and coronatine synthesis $[43,44]$, respectively. Finally, the hybrid HK PSPTO2896 contains an N-terminal LOV (light, oxygen, or voltage) domain and is blue-light-activated [54].

Bacteria with large genomes are disproportionately enriched in regulatory proteins involved in transcription control and signal transduction compared to medium and small-size genomes, and typically have complex regulatory networks relative to bacteria with smaller genomes [55-57]. The existence of large numbers of HKs and RRs in $P$. syringae strongly suggests that TCS proteins play important regulatory roles in the adaptation of this bacterium to different plant and non-plant environments. Comparative genomics of closely related species of pathogenic bacteria represents a powerful tool for the identification of genes potentially involved in host specificity and pathogenesis. The availability of the genome sequences of Pto DC3000, Psy B728a and Pph 1448A provides us with the unique 
capability of comparing the complement of TCS proteins in these P. syringae pathovars that differ in host range and other interactions with plants. This comparative genomic analysis reveals a core of orthologues and important differences in TCS genes between $P$. syringae pathovars. It is especially worth noting the high number of genes encoding orphan HKs and RRs in these genomes. Moreover, differences in the repertoires of TCS proteins are likely to facilitate the adaptation of $P$. syringae pathovars to different plant hosts and/or could be responsible for the different disease characteristics induced. Consequently, the TCS proteins unique to each $P$. syringae pathovar are interesting targets for future investigations to identify TCS proteins involved in the different host ranges and/or plant pathogenesis. However, the challenge remains to associate these differences in TCS proteins to specific traits of $P$. syringae pathovars. Additionally, pathovar-specific differences in gene content might be used to design targeted approaches for disease control and could allow the precise PCR-based diagnosis of bacterial diseases [58].

Analysis of the regulatory functions, molecular mechanisms and signal transduction pathways of TCS proteins should contribute to the understanding of the complex events that occur in $P$. syringae during pathogenesis and adaptation to different plant hosts and different nonplant environments. Rapid progress in the study of TCS proteins is being made by the combination of molecular genetic approaches with genome-scale analysis [59]. Genetic and biochemical studies are necessary to further explore the signal transduction pathways mediated by some of these TCS proteins at the molecular level: construction and analysis of deletion mutants in TCS genes in order to determine the signals sensed by the HK and the targets for the RR of each system. In addition, the application of more extensive analysis with global methods, such as DNA microarray studies reported for B. subtilis [60] and S. pneumoniae [61], might allow defining the regulons and the potential regulatory functions of TCS proteins in response to environmental signals. Furthermore, unravelling these signal transduction pathways could potentially lead to the design of innovative strategies to control $P$. syringae. In conclusion, this comparative genomic analysis constitutes a basis for future functional genomic analysis of $P$. syringae to establish which TCS proteins participate in the pathogenesis and the adaptation to different plant and non-plant environments.

\section{Methods}

Identification of TCS proteins in P. syringae genomes

The identification of HKs and RRs is based on the computational domain analysis of protein sequences. The approach used to identify putative HKs and RRs from the complete genome sequences of Psy B728a, Pto DC3000 and $P p h 1448 \mathrm{~A}$ was similar to that described previously
[33] with slight modification. Briefly, five different HMM profiles (accession numbers PF00512, PF07568, $\underline{\mathrm{PF} 07730}, \underline{\mathrm{PF} 07536}$ and PF06580) were found in Pfam database that target different families of HKs (HisKA, HisKA_2, HisKA_3, HWE_HK and His_kinase). The HWE_HK domain is defined by the absence of a recognizable $\mathrm{F} \mathrm{box}$, and the presence of a highly conserved $\mathrm{H}$ residue and a WxE motif within the N and G1 boxes of the Cterminal transmitter domain, respectively [4]. These five different HMM profiles were used to recognize the different HKs in the P. syringae genomes, and hits with a E-value below a selected cut-off $\left(10^{-6}\right)$ were extracted. A profile HMM downloaded from Pfam protein families database [62], which targets the RR REC domain (accession number PF00072), was used to recognize the RRs in each $P$. syringae genome. Hits with an E-value below a selected cut-off $\left(10^{-12}\right)$ were extracted. Additionally, the CheA HK of Escherichia coli [31] was used as template in BLASTP searches to identify CheA-like HKs in the P. syringae genomes and hits with an E-value below a selected cut-off $\left(10^{-10}\right)$ were extracted. Hybrid HKs (REC-HKs) were determined by the presence of complete HK transmitter and REC domains in a single protein. Detection of orthologues of the identified $\mathrm{HKs}$ and RRs between the genomes of Psy B728a, Pto DC3000 and Pph 1448A was determined by BLASTP [63] based on the reciprocal best hits of each $P$. syringae genome against each other genome, completed by the phylogenetic analyses. Finally, functional domains of the HKs and RRs were identified by search the Conserved Domain Databases (CDD) with Reverse Specific Position BLAST [64].

\section{Sequence alignment and phylogenetic analysis}

Multiple sequence alignments and phylogenetic trees of HKs and RRs were constructed using the ClustalW program [65], and aligned sequences were imported into the MEGA 3.1 program [66] where phylogenetic trees were inferred. Default parameters were used. Phylogenetic trees were subdivided into groups of orthologues, and co-clustering with members of specific TCS proteins allowed a definitive assignation to a given HK type or RR family.

\section{List of abbreviations}

TCS: two-component system

HK: histidine kinase

RR: response regulator

HMM: Hidden Markov Model

HTH: helix-turn-helix

ECF: extracytoplasmic function 
EBP: enhancer-binding protein

Psy: Pseudomonas syringae pv. syringae

Pto: P. syringae pv. tomato

Pph: P. syringae pv. phaseolicola

REC: receiver

PHY: phytochrome

LOV: light, oxygen, and voltage

\section{Authors' contributions}

DWU and JAO designed and coordinated the project. JLL, KK and OR performed the bioinformatics studies and interpreted the results. JAO wrote the manuscript. All authors have read and approved the final manuscript.

\section{Additional material}

\section{Additional file 1}

$H K s$ in the genomes of $\mathrm{P}$. syringae $p v$. syringae $B 728 a, p v$. tomato DC3000 and $p v$. phaseolicola 1448A.

Click here for file

[http://www.biomedcentral.com/content/supplementary/1471-

2164-8-397-S1.xls]

\section{Additional file 2}

$R R$ s in the genomes of $\mathrm{P}$. syringae $p v$. syringae $B 728 a, p v$. tomato DC3000 and $p v$. phaseolicola 1448A.

Click here for file

[http://www.biomedcentral.com/content/supplementary/14712164-8-397-S2.xls]

\section{Acknowledgements}

JLL was a recipient of a predoctoral fellowship from the Public University of Navarra. JAO was supported by the Ramón y Cajal Programme and Complementary Action Grant BIO2006-28484-E of the Spanish Ministerio de Educación y Ciencia (MEC). JLL and JAO thank Antonio G Pisabarro and Lucía Ramírez for continued support. DWU and KK would like to acknowledge funding by the Danish Center for Scientific Computing.

\section{References}

I. Stock AM, Robinson VL, Goudreau PN: Two-component signal transduction. Annu Rev Biochem 2000, 69:183-215.

2. Galperin MY: Bacterial signal transduction network in a genomic perspective. Environ Microbiol 2004, 6:552-567.

3. Hoch JA: Two-component and phosphorelay signal transduction. Curr Opin Microbiol 2000, 3:165-170.

4. Karniol B, Vierstra RD: The HWE histidine kinases, a new family of bacterial two-component sensor kinases with potentially diverse roles in environmental signalling. J Bacteriol 2004, I 86:445-453.

5. Garzon A, Parkinson JS: Chemotactic signalling by the PI phosphorylation domain liberated from the CheA histidine kinase of Escherichia coli. J Bacteriol 1996, I78:6752-6758.
6. Bilwes AM, Alex LA, Crane BR, Simon MI: Structure of CheA, a signal transducing histidine kinase. Cell 1999, 96:|3|-|4|.

7. Grebe TW, Stock JB: The histidine protein kinase superfamily. Adv Microb Physiol 1999, 4l: 139-227.

8. Kim D, Forst S: Genomic analysis of the histidine kinase family in bacteria and archaea. Microbiology 2001, I47(Pt 5): I 197-1212.

9. Witchurch $\mathrm{CB}, \mathrm{Alm} \mathrm{RA}$, Mattick JS: The alginate regulator AlgR and an associated FimS are required for twitching motility in Pseudomonas aeruginosa. Proc Natl Acad Sci USA 1996, 93:9839-9843.

10. Anantharaman V, Aravind L: Application of comparative genomics in the identification and analysis of novel families of membrane-associated receptors in bacteria. BMC Genomics 2003, 4:34.

II. Mascher T, Helmann JD, Unden G: Stimulus perception in bacterial signal-transducing histidine kinases. Microbiol Mol Biol Rev 2006, 70:910-938.

12. Galperin MY: Structural classification of bacterial response regulators: diversity of output domains and domain combinations. J Bacteriol 2006, I88:4169-4I82.

13. Ulrich LE, Koonin EV, Zhulin IB: One-component systems dominate signal transduction in prokaryotes. Trends Microbiol 2005, 13:52-56.

14. Appleby JL, Parkinson JS, Bourret RB: Signal transduction via the multistep phosphorelay: not necessarily a road less traveled. Cell 1996, 86:845-848.

I5. Mizuno T, Kaneko T, Tabata S: Compilation of all genes encoding bacterial two-component signal transducers in the genome of the cyanobacterium, Synechocystis sp. Strain PCC 6803. DNA Res 1996, 3:407-4I4.

16. Mizuno T: Compilation of all genes encoding two-component phosphotransfer signal transducers in the genome of Escherichia coli. DNA Res 1997, 4:161-168.

17. Fabret C, Feher VA, Hoch JA: Two-component signal transduction in Bacillus subtilis: how one organims sees its world. J Bacteriol 1999, I 81: 1975-1983.

18. Ashby MK: Survey of the number of two-component response regulator genes in the complete and annotated genome sequences of prokaryotes. FEMS Microbiol Lett 2004, 23 I (2):277-28I.

19. Ashby MK, Houmard J: Cyanobacterial two-component proteins: structure, diversity, distribution, and evolution. Microbiol Mol Biol Rev 2006, 70:472-509.

20. de Been M, Francke C, Moezelaar R, Abee T, Siezen RJ: Comparative analysis of two-component signal transduction systems of Bacillus cereus, Bacillus thuringiensis and Bacillus anthracis. Microbiology UK 2006, I 52:3035-3048.

21. Hirano SS, Upper CD: Bacteria in the leaf ecosystem with emphasis on Pseudomonas syringae-a pathogen, ice nucleus and epiphyte. Microbiol Mol Biol Rev 2000, 64:624-653.

22. Boch J, Joardar V, Gao L, Robertson TL, Lim M, Kunkel BN: Identification of Pseudomonas syringae pv. tomato genes induced during infection of Arabidopsis thaliana. Mol Microbiol 2002, 44:73-88.

23. Jensen LJ, Skovgaard M, Sicheritz-Pontén T, Hansen NT, Johansson $H$, Jørgensen MK, Kiil K, Hallin PF, Ussery DW: Comparative genomics of four Pseudomonas species. In The Pseudomonas. Genomics, Life Style and Molecular Architecture Volume I. Edited by: Ramos JL. New York: Kluwer Academic/Plenum Publishers; 2004:I39- 164.

24. Oguiza JA, Kiil K, Ussery DW: Extracytoplasmic function sigma factors in Pseudomonas syringae. Trends Microbiol 2005, I 3:565-568.

25. Buell CR, Joardar V, Lindeberg M, Selengut J, Paulsen IT, Gwinn ML, Dodson RJ, Deboy RT, Durkin AS, Kolonay JF, Madupu R, Daugherty S, Brinkac L, Beanan MJ, Haft DH, Nelson WC, Davidsen T, Zafar N, Zhou L, Liu J, Yuan Q, Khouri H, Fedorova N, Tran B, Russell D, Berry K, Utterback T, Van Aken SE, Feldblyum TV, D'Ascenzo M, Deng WL, Ramos AR, Alfano JR, Cartinhour S, Chatterjee AK, Delaney TP, Lazarowitz SG, Martin GB, Schneider DJ, Tang X, Bender CL, White $O$, Fraser CM, Collmer A: The complete genome sequence of the Arabidopsis and tomato pathogen Pseudomonas syringae pv. tomato DC3000. Proc Natl Acad Sci USA 2003, 100:10181-10186.

26. Feil H, Feil WS, Chain P, Larimer F, DiBartolo G, Copeland A, Lykidis A, Trong S, Nolan M, Goltsman E, Thiel J, Malfatti S, Loper JE, Lapidus A, Detter JC, Land M, Richardson PM, Kyrpides NC, Ivanova N, 
Lindow SE: Comparison of the complete genome sequences of Pseudomonas syringae pv. syringae B728a and pv. tomato DC3000. Proc Natl Acad Sci USA 2005, I 02: I I 064-I I 069.

27. Joardar V, Lindeberg M, Jackson RW, Selengut J, Dodson R, Brinkac LM, Daugherty SC, Deboy R, Durkin AS, Giglio MG, Madupu R, Nelson WC, Rosovitz MJ, Sullivan S, Crabtree J, Creasy T, Davidsen T, Haft DH, Zafar N, Zhou L, Halpin R, Holley T, Khouri H, Feldblyum T, White O, Fraser CM, Chatterjee AK, Cartinhour S, Schneider DJ, Mansfield J, Collmer A, Buell CR: Whole-genome sequence analysis of Pseudomonas syringae pv. phaseolicola I448A reveals divergence among pathovars in genes involved in virulence and transposition. J Bacteriol 2005, 1 87:6488-6498.

28. Galperin MY: A census of membrane-bound and intracellular signal transduction proteins in bacteria: bacterial IQ, extroverts and introverts. BMC Microbiol 2005, 5:35.

29. Alm E, Huang K, Arkin A: The evolution of two-component systems in bacteria reveals different strategies for niche adaptation. PLoS Comput Biol 2006, 2:e I43.

30. Zhang W, Shi L: Distribution and evolution of multiple-step phosphorelay in prokaryotes: lateral domain recruitment involved in the formation of hybrid-type histidine kinases. Microbiology UK 2005, I 5 I:2159-2173.

31. Kofoid EC, Parkinson JS: Tandem translation in the cheA locus of Escherichia coli. J Bacteriol 1991, 173:2116-2119.

32. Kill K, Binnewies TT, Sicheritz-Pontén T, Willenbrock H, Hallin PF, Wassenaar TM, Ussery DW: Genome update: sigma factors in 240 bacterial genomes. Microbiology UK 2005, I 5 I:3 I47-3 I 50.

33. Kiil K, Ferchaud JB, David C, Binnewies TT, Wu H, Sicheritz-Pontén T, Willenbrock $H$, Ussery DW: Genome update: distribution of two-component transduction systems in $\mathbf{2 5 0}$ bacterial genomes. Microbiology UK 2005, I 5 I :3447-3452.

34. Hutchings MI, Hoskisson PA, Chandra G, Buttner MJ: Sensing and responding to diverse extracellular signals? Analysis of the sensor kinases and response regulators of Streptomyces coelicolor A3(2). Microbiology UK 2004, I 50:2795-2806.

35. Galperin MY, Nikolskaya AN, Koonin EV: Novel domains of the prokaryotic two-component signal transduction systems. FEMS Microbiol Lett 200 I, 203: I I-2I.

36. Aravind L, Ponting CP: The GAF domain: and evolutionary link between diverse phototransducing proteins. Trends Biochem Sci 1997, 22(1 2):458-459.

37. Ho YS, Burden LM, Hurley JH: Structure of the GAF domain, a ubiquitous signalling motif and a new class of cyclic GMP receptor. EMBO J 2000, 19:5288-5299.

38. Karniol B, Wagner JR, Walker JM, Vierstra RD: Phylogenetic analysis of the phytochrome superfamily reveals distinct microbial subfamilies of photoreceptors. Biochem J 2005 392:103-116.

39. Studholme DJ, Dixon R: Domain Architectures of $\sigma^{54}$-Dependent Transcriptional Activators. J Bacteriol 2003, I 85: 1757-I767.

40. Morett $E$, Segovia L: The $\sigma^{54}$ bacterial enhancer-binding protein family: mechanism of action and phylogenetic relationship of their functional domains. J Bacteriol 1993, I 75:6067-6074.

4I. Grimm C, Panopoulos NJ: The predicted protein product of a pathogenicity locus from Pseudomonas syringae pv. phaseolicola is homologous to a highly conserved domain of several prokaryotic regulatory proteins. J Bacteriol 1989, | 7 |:503|-5038.

42. Xiao Y, Heu S, Yi J, Lu Y, Hutcheson SW: Identification of a putative alternative sigma factor and characterization of a multicomponent regulatory cascade controlling the expression of Pseudomonas syringae pv. syringae Pss6 I hrp and hrmA genes. J Bacteriol 1994, 1 76:1025-1036.

43. Liyanage H, Palmer DA, Ullrich M, Bender CL: Characterization and transcriptional analysis of the gene cluster for coronafacic acid, the polyketide component of the phytotoxin coronatine. Appl Environ Microbiol 1995, 6 I:3843-3848.

44. Ullrich M, Peñaloza-Vázquez A, Bailey A, Bender CL: A modified two-component regulatory system is involved in temperature-dependent biosynthesis of the Pseudomonas syringae phytotoxin coronatine. J Bacteriol 1995, 177:6160-6169.

45. Cotter PA, Jones AM: Phosphorelay control of virulence gene expression in Bordetella. Trends Microbiol 2003, I I:367-373.

46. Drenkard E, Ausubel FM: Pseudomonas biofilm formation and antibiotic resistance are linked to phenotypic variation. Nature 2002, 4 I 6:740-743.
47. Lee SH, Angelichio MJ, Mekalanos JJ, Camilli A: Nucleotide sequence and spatiotemporal expression of the Vibrio cholerae vieSAB genes during infection. I Bacteriol 1998, I 80:2298-2305

48. Morris CE, Kinkel LL, Xiao T, Prior P, Sands DC: Surprising niche for the plant pathogen Pseudomonas syringae. Infect Genet Evol 2007, 7:84-92.

49. Hutcheson SW, Bretz J, Sussan T, Jin S, Pak K: Enhancer-binding HrpR and HrpS interact to regulate hrp-encoded type III protein secretion in Pseudomonas syringae strains. J Bacteriol 2001, 1 83:5589-5598.

50. Chatterjee A, Cul Y, Yang H, Collmer A, Alfano JR, Chatterjee AK: GacA, the response regulator of a two-component system, acts as a master regulator in Pseudomonas syringae pv. tomato DC3000 by controlling regulatory RNA, transcriptional activators, and alternate sigma factors. Mol PlantMicrobe Interact 2003, I 6: I 106-I I I7.

5I. Xiao Y, Lan L, Yin C, Deng X, Baker D, Zhou JM, Tang X: Two-component sensor RhpS promotes induction of Pseudomonas syringae type III secretion system by repressing negative regulator RhpR. Mol Plant Microbe Interact 2007, 20:223-234.

52. Rich JJ, Kinscherf TG, Kitten T, Willis DK: Genetic evidence that the gacA gene encodes the cognate response regulator for the lemA sensor in Pseudomonas syringae. J Bacteriol 1994, I 76:7468-7475

53. Mills SD, Jasalavich CA, Cooksey DA: A two-component regulatory system required for copper-inducible expression of the copper resistance operon of Pseudomonas syringae. J Bacteriol 1993, I75:1656-1664.

54. Swartz TE, Tseng TS, Frederickson MA, Paris G, Comerci DJ, Rajashekara G, Kim JG, Mudgett MB, Splitter GA, Ugalde RA, Goldbaum FA, Briggs WR, Bogomolni RA: Blue-light-activated histidine kinases: two-component sensors in bacteria. Science 2007, 31 7:1090-1093.

55. Stover CK, Pham XQ, Erwin AL, Mizoguchi SD, Warrener P, Hickey MJ, Brinkma FS, Hufnagle WO, Kowalik DJ, Lagrou M, Garber RL, Goltry L, Tolentino E, Westbrock-Wadman S, Yuan Y, Brody LL, Coulter SN, Folger KR, Kas A, Larbig K, Lim R, Smith K, Spencer D, Wong GK, Wu Z, Paulsen IT, Reizer J, Saier MH, Hancock RE, Lory $\mathrm{S}$, Olson MV: Complete genome sequence of Pseudomonas aeruginosa PAOI, an opportunistic pathogen. Nature 2000, 406:959-964.

56. van Nimwegen E: Scaling laws in the functional content of genomes. Trends Genet 2003, 19:479-484.

57. Kostantinidis KT, Tiedje JM: Trends between gene content and genome size in prokaryotic species with larger genomes. Proc Natl Acad Sci USA 2004, I 0 I:3 160-3 I 65.

58. Büttner D, Noël L, Thieme F, Bonas U: Genomic approaches in Xanthomonas campestris pv. vesicatoria allow fishing for virulence genes. J Biotechnol 2003, I 06:203-2|4.

59. Seshasayee AS, Bertone P, Fraser GM, Luscombe NM: Transcriptional regulatory networks in bacteria: from input signals to output responses. Curr Opin Microbiol 2006, 9:5 I I-5I9.

60. Kobayashi K, Ogura M, Yamaguchi H, Yoshida KI, Ogasawara N, Tanaka T, Fujita Y: Comprehensive DNA microarray analysis of Bacillus subtilis two-component regulatory $200 \mathrm{I}$ systems. J Bacteriol 200I, I 83:7365-7370.

6I. Throup JP, Koretke KK, Bryant AP, Ingraham KA, Chalker AF, Ge Y, Marra A, Wallis NG, Brown JR, Holmes DJ, Rosenberg M, Burnham MKR: A genomic analysis of two-component signal transduction in Streptococcus pneumoniae. Mol Microbiol 2000, 35:566-576.

62. Bateman A, Coin L, Durbin R, Finn RD, Hollich V, Griffiths-Jones S, Khanna A, Marshall M, Moxon S, Sonnhammer EL, Studholme DJ, Yeats C, Eddy SR: The Pfam protein families database. Nucleic Acids Res 2004, 32:DI38-D I4I

63. Altschul SF, Madden TL, Schäffer AA, Zhang J, Zhang Z, Miller W, Lipman DJ: Gapped BLAST and PSI-BLAST: a new generation of protein database search programs. Nucleic Acids Res 1997, 25:3389-3402.

64. Marchler-Bauer A, Anderson JB, DeWeese-Scott C, Fedorova ND, Geer LY, He S, Hurwitz DI, Jackson JD, Jacobs AR, Lanczycki CJ, Liebert CA, Liu C, Madej T, Marchler GH, Mazumder R, Nikolskaya AN, Panchenko AR, Rao BS, Shoemaker BA, Simonyan V, Song JS, Thiessen PA, Vasudevan S, Wang Y, Yamashita RA, Yin JJ, Bryant SH: CDD: a 
curated Entrez database of conserved domain alignments. Nucleic Acids Res 2003, 3 I:383-387.

65. Thompson JD, Higgins DG, Gibson TJ: CLUSTAL W: improving the sensitivity of progressive multiple sequence alignment through sequence weighting, position-specific gap penalties and weight matrix choice. Nucleic Acids Res 1994, 22:4673-4680.

66. Kumar S, Tamura K, Nei M: MEGA3: integrated software for molecular evolutionary genetics analysis and sequence alignment. Brief Bioinform 2004, 5:150-163.

Publish with Bio Med Central and every scientist can read your work free of charge

"BioMed Central will be the most significant development for disseminating the results of biomedical research in our lifetime. " Sir Paul Nurse, Cancer Research UK

Your research papers will be:

- available free of charge to the entire biomedical community

- peer reviewed and published immediately upon acceptance

- cited in PubMed and archived on PubMed Central

- yours - you keep the copyright

Submit your manuscript here:

http://www.biomedcentral.com/info/publishing_adv.asp
BioMedcentral

Page 12 of 12

(page number not for citation purposes) 